tion by diploma (4 April, p 890). One of the academically brightest men in my own year was fired from four locum jobs within a fortnight of getting his degree. He lasted exactly one morning in one hospital, and in the last, a country practice, a deputation of patients went on the fourth day to the solicitor brother of the holidaying doctor to summon him home.

When my father suddenly died in his 40 s, leaving my mother and myself in much reduced circumstances, I had to qualify by diploma for financial reasons. My fellow student, Sir John Charnley, also qualified early by diploma, though for a quite different reason. What matters is not how we first got on to the Medical Register but what we did with our lives afterwards.

\section{WILLIAM S PARKER}

Brighton BN1 8TD

SIR,-Mr Richard Wakeford implies that qualification as a doctor recognised by the General Medical Council should occur only as a result of passing the examinations set by universities. I should like to take a contrary view.

Provided that there is a recognised, respected, and competent body that regulates entry into the profession, as the General Medical Council does, there is no reason why that body should not recognise non-university examining bodies. Indeed, it is probably healthy for an independent service profession such as medicine not to be too closely tied to the university system as this may reduce the influence that the members of the profession as a whole may bring to bear in determining their own professional standards and competences. I would go further and state that the General Medical Council and examining bodies should explore recognising prequalification medical training that could be carried out by nonuniversity bodies (as happened in the past). Clearly, the council must be careful that it does not allow medical training to become too technical or mechanistic.

Interestingly, neither vocational training nor the qualifying examinations to become a barrister or solicitor are carried out in or by universities (though universities confer academic law degrees). In other words, it is not possible to become a barrister or solicitor with the legal equivalent of an MB BS university degree, and the Law Society actually arranges the specific training and qualifying examinations itself.

In the final analysis if a training or examining body with delegated authority fails to apply the standards set by a national "council" it is up to that body to withdraw its recognition. I, for one, am confident that for medicine the General Medical Council now exercises its responsibility in these matters properly and with care.

E Josse

British Postgraduate Medical Federation, North Middlesex Hospital,

London N18 1QX

\section{Abdominal aortic aneurysms}

SIR,-Mr N F Gowland Hopkins (28 March, p 790) is not sufficiently forceful in advocating elective surgery for asymptomatic abdominal aortic aneurysms. This must now be regarded as the only appropriate treatment in all patients except the very old or those with severe coexistent disease likely to increase operative mortality substantially.

At least half of all patients known to have an abdominal aortic aneurysm will die from its rupture if elective surgery is withheld. Even in know they are wrong to quote a $12.5 \%$ mortality patients considered to be too old, too feeble, or too much at risk from associated cardiopulmonary or renal disease to undergo surgery $52 \%$ die from rupture of their aneurysm. ' Similarly, in one study $42 \%$ of all deaths in patients rejected for elective surgery because of small aneurysm size or excessive cardiac risk were due to rupture of the aneurysm despite one patient in every six with a rupture being saved by emergency surgery. ${ }^{2}$

In addition, elective surgery for an abdominal aortic aneurysm now carries an operative mortality of well under $5 \%$ in specialist vascular surgical units. The operative mortality of up to $10 \%$ quoted by $\mathrm{Mr}$ Gowland Hopkins has little relevance for current practice as the studies supporting this figure include patients operated on more than a quarter of a century ago. The Oxford experience illustrates the continuing improvement in operative survival. Between 1979 and 1984 an average of 14 elective aneurysm operations were performed yearly, with an operative mortality of $4 \cdot 2 \%{ }^{3}$ Currently, there are 33 elective aneurysm operations a year, with an operative mortality of $2 \cdot 1 \%$.

No patient with an abdominal aortic aneurysm should now be denied the opportunity of consultation with an experienced vascular surgeon to assess his or her suitability for the lifesaving operation of elective replacement of the aneurysm.

Nuffield Department of Surgery,

JaCk Collin John Radcliffe Hospital, Oxford OX3 9DU

1 Darling RC, Messina CR, Brewster DC, Ottinger LW. Autopsy study of unoperated abdominal aortic aneurysms. The case fo early resection. Circulation 1977;56(3 Pt 2 suppl): $11161-4$.

2 Cronenwett JL, Murphy TF, Zelenock GB, et al. Actuarial analysis of variables associated with rupture of small abdomina analysis of variables associated with rupture

3 Campbell WB, Collin J, Morris PJ. The mortality of abdominal aortic aneurysm. Ann R Coll Surg Engl 1986;68:275-8.

\section{Inoperable aortic stenosis in the elderly:} benefit from percutaneous transluminal valvuloplasty

SIR,-We must emphasise to the correspondents (21 February, p 510) on our paper (10 January, p 83) that we were not advocating valvuloplasty as an alternative in patients suitable for aortic valve replacement but suggesting that it may improve the wellbeing of patients who are not surgical candidates. We adopted a practical but cautious viewpoint.

Dr J E Sanderson and colleagues (p 510) have in a district hospital followed a similar protocol to ours, and we are encouraged by their good results. The natural history of non-surgical candidates is poor, with only a $25 \%$ survival at three years, so valvuloplasty may offer not only a better quality but also a better quantity of life. ${ }^{1}$ Nevertheless, follow up must be arranged because the nature of the disease, we believe, leads to restenosis.

Early reports suggest a restenosis rate of $20 \%$ at six months, ${ }^{2}$ but this is less if the aortic valve area is increased to greater than $1 \mathrm{~cm}^{2}$. This is why we do not advocate valvuloplasty for surgical candidates, though when further long term results become available a clinical trial may be justified. We agree that one of the attractions of the procedure is that surgical cover is not necessary.

Mr Francis Wells and colleagues do our caution a disservice. We accept that immediate mortality in suitable cases is now just under $5 \%$ but there is also a recognised morbidity in this age group. We are, however, not proposing valvuloplasty as an alternative procedure and we are dealing with sick and frail people with severe disease whose valve areas average $0.3 \mathrm{~cm}^{2}$. Mr Wells and colleagues figure in our series as they are aware of our 15 cases presented at the American Heart Association and British Cardiac Society with still only the one death. We have now a series of 30 patients with one early death and have refined the procedure to a 30 minute exercise with $x$ ray exposure of less than 10 minutes. We do not wish to claim a better mortality figure $(3 \cdot 3 \%)$ than surgery because we are not dealing with the same patients. We do not subscribe to the more generalised use of aortic valvuloplasty which appears to be advocated by the French. ${ }^{3}$ We agree that inflation time should be brief and currently use 10-15 seconds with $20 \mathrm{~mm}$ balloons.

Dr I R Starkey and colleagues share with us the need to monitor results and carefully select patients. We will shortly be reporting our one year follow up and would like to invite anyone interested in performing valvuloplasty to observe a procedure in our unit. We have learnt to circumvent the difficulties and see no reason why others should not benefit from our experience. We have established a register and hope as many operators as possible will join us in defining precisely the indications for, benefits of, and long term success of aortic valvuloplasty.

Drs D F Ettles and J L Gibbs (7 March, p 648) mention the difficulties of recording transaortic Doppler blood velocities when a catheter is in place across the aortic valve. In our patients the effects of intracavity acoustic interference were limited because intraoperative recordings were made only with a guide wire positioned across the valve. In addition, continuous wave Doppler ${ }^{4}$ rather than pulsed Doppler mapping was used to monitor changes in aortic regurgitation. The integrity of the intraoperative measurements was verified by comparison with the relevant Doppler recordings before and after the procedure and prevalvuloplasty aortography. An increase in the intensity or rate of deceleration of the aortic regurgitant flow velocity pattern was considered compatible with deteriorating aortic regurgitation. While accepting that pulsed Doppler does have limitations in measuring aortic regurgitation, we believe that continuous wave Doppler (as used in this study) is likely to be superior, especially when measuring changes within individual patients.

MARK J MONAGHaN GRAHAM JACKSON DAVID E JEWITT

\section{Cardiac Department,}

London SE5 9RS

1 O'Keefe JH, Vlietstra MB, Holmes DR, Bailey KR. Natura history of candidates for balloon aortic valvuloplasty. Fournal of the American College of Cardiology 1987;9:195A.

2 Letac B, Berland J, Rachid M, et al. Late haemodynamic evaluation after percutaneous aortic valvuloplasty in adults with aortic stenosis. Fournal of the American College of Cardiology 1987;9:14A. aortic valvuloplasty in adult aortic stenosis: results in 130 patients. Foumal of the American College of Cardiology 1987;9. $13 \mathrm{~A}$

Labovitz AJ, Ferrara RP, Morton JK, Bryg RJ, Mrosek DG continuous wave Doppler echocardiography. Fournal of the American College of Cardiology 1986;8:1341-7.

Masuyama T, Kazuhisa K, Kitababtabe A, et al. Non-invasive evaluation of aortic regurgitation by continuous wave Doppler echocardiography. Circulation 1986;73:460-6.

\section{Overuse of monitoring of blood} concentrations of antiepileptic drugs

SIR,-Dr David Chadwick's leading article on circulating anticonvulsant monitoring (21 March, p 723) is timely, but overuse of the service is only a symptom and not the disease. ${ }^{1}$ The fundamental flaw lies in the unrealistic view taken by the
King's College Hospital,

3 Cribier A, Berland J, Savin T, et al. Percutaneous transluminal Williams GA. Quantitive evaluation of aortic insufficiency by 